Please submit all manuscripts (in duplicate) and inquiries to: Prof. Anand A. Yang, Editor, Peasant Studies, Department of History, University of Utah, Salt Lake City, UT 84112.

\title{
NEWS OF SCHOLARS
}

\section{Ph.D. Dissertations Completed}

Ali A. Masalehdan [U of Massachusetts, Amherst]: Political Culture and Political Development: An Analysis of the Institution Building Process in Iran.

Evelyn A. Menconi [Boston U]: An Analysis of Teachers' Perceptions of the Arab World.

Athena M. DeFabo [George Washington U]: The Aegean Island Question and Greece: A Diplomat ic History, 1911-1914.

Barbara Schmitz [New York U]: Miniature Painting in Harāt, 1570-1640. Michael J.L. Young [U of Melbourne, 1962]: The Arabian System of Medicine in the Thirteenth Century.

James G. Flynn [U of Melbourne, 1967]: St. Thomas' Use of Islamic Sources on the Nature and Attributes of God.

Terence C. Falla [U of Melbourne, 1972]: Studies in Peshitta Gospels: An Examination of Four Groups in the Peshitta Gospel Words and their Contribution to the Study of the Peshitta as a Revision.

Hanneh D. Deeb [U of Melbourne, 1975]: The Popular Proverbs of Lebanon. Ibrahim Ata [U of Melbourne, 1980]: The Lebanese Community in Melbourne.

Vincent A. Clark [U of Melbourne, 1980]: A Study of New Safaitic Inscriptions from Jordan.

Jeremy Salt [U of Melbourne, 1980]: Christian Imperialism in Turkey, 1876-1908.

\section{Dissertations in Progress}

Carol Bier [New York U]: Dionysiac Imagery in the Art of Iran.

Mary Maugham [U of Utah]: Retaliatory Raids and Terrorism: Tactics and Strategies in the Arab-israeli Conflict.

Hussein El-Khafaifi [U of Utah]: A Descriptive Analys is of Benghazi Arabic.

Mohammed Ben-Ghaly [U of Utah]: Comparative Study in Arabic and Persian Mystical Poetry.

Lida Andisheh [U of Utah]: Life and Work of Abbas lqbal Asht ${ }^{C}$ iani. Balkees, al-Najjar [U of Utah]: Aspectical Verbs in Kuwaiti Arabic. Abdulmatlub Abdulmatlub [U of Utah]: The Modern Libyan Short Story: A Comparative Study.

\section{Appointments and Promotions}

Yael Feldman - Assist. Professor of Hebrew Language and Literature, Columbia University, New York City.

Marlee Meriwether - Assist. Professor of History, Denison University. Willa Dawson - Lecturer, English Linguistics, Kuwait University. Hani Fares - [Kuwait U]: Visiting Professor, Institute of Islamic Studies, McGill University, 1981-1982.

David Ede - [W. Michigan U]: Visiting Professor, Inst. of islamic Studies, McGill University, 1981-1982.

John Damos

- Professor of Political Science, Portland Science University. 